REVISTA DE LITERATURA E CULTURA RUSSA

\title{
Entrevista com Michael Löwy (CNRS): literatura russa, filosofia e messianismo
}

Autor: Jimmy Sudário Cabral Edição: RUS Vol. 12. № 18

Data: Abril de 2021 


\section{Entrevista com Michael Löwy (CNRS): literatura russa, filosofia e messianismo}

Jimmy Sudário Cabral*

* Professor no Departamento e no Programa de Pós-Graduação em Ciência da Religião da Universidade Federal de Juiz de Fora. Coordenador do Núcleo de Estudos da Religião em Dostoiévski e Tolstói, Nerdt. htps://www.ufjf.br/nerdt/; E-mail: sudarioc@hotmail.com; https://orcid.org/0000-00016598-0554

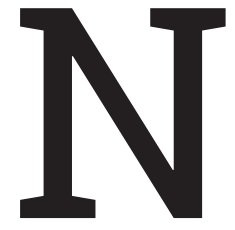

a história da recepção de Dostoiévski e Tolstói no pensamento filosófico moderno, uma tradição filosófica de origem judaico-alemã tem um papel de destaque. Produto de uma "síntese espiritual" singular, como observou Michael Löwy, o pensamento de Franz Kafka, Georg Lukács, Ernst Bloch e Walter Benjamin apareceu na Modernidade como o signo de reinvindicação messiânica por um socialismo libertário, radical e revolucionário. ${ }^{1}$ Trazendo em comum a experiência de não estarem reconciliados com o mundo e com a história, ${ }^{2}$ esses intelectuais judeus da Europa Central tiveram como fontes privilegiadas da sua visão de mundo o "messianismo judaico" e o "romantismo alemão" ${ }^{3} \mathrm{O}$ conceito religioso de redenção e a

1 LÖWY, M. Redenção e utopia: o judaísmo libertário na Europa Central. São Paulo: Perspectiva, 2020.

2 BOURETZ, P. Témoins du futur. Philosophie et messianisme. Paris: Éditions Gallimard, 2003. p. 18.

3 LÖWY, M. Redenção e utopia: o judaísmo libertário na Europa Central. São Paulo: Perspectiva, 2020. 
noção política de utopia libertária conjugaram-se na trajetória dessa intelligentsia judaico-alemã, que promoveu uma reconfiguração do pensamento filosófico sem precedentes. É sabido que as obras de Dostoiévski e Tolstói atravessam o imaginário messiânico e utópico dessa geração de intelectuais revolucionários e, como afirmou assertivamente o professor Michael Löwy, "o utopista Bloch encontra em Dostoiévski elementos que legitimam $O$ princípio esperança: 'Aliócha Karamázov seria um precursor do "reino religioso da justiça' [...]". Tal constatação encontra-se no bojo de uma fortuna crítica acumulada nas obras de Löwy e abre caminhos de análises que ainda estão por serem feitas em relação à recepção da literatura russa na filosofia judaica moderna.

Michael Löwy é diretor de pesquisas no Centre National de la Recherche Scientifique (CNRS) e figura entre os mais destacados pensadores da atualidade. Filósofo marxista, sua obra oferece um raro entrelaçamento entre socialismo e surrealismo e estabelece uma aproximação rigorosa entre filosofia e literatura. ${ }^{4} \mathrm{~A}$ acuidade com que Löwy interpreta o messianismo e o romantismo de tradição judaico-alemã, a negatividade trágica e a reinvindicação ética e humana trazidas à luz por tal tradição apresentam-nos um estado de ânimo revolucionário e libertário que só tem equivalentes nos vislumbres de ruptura utópica e messiânica encontrados no grande romance russo. O conceito de "romantismo anticapitalista", o qual possibilitou uma leitura da tradição romântica em chave revolucionária, pode ser interpretado como o fil rouge que conecta o mundo de Tolstói e Dostoiévski aos ímpetos utópico-messiânicos do judaísmo moderno. A recepção da literatura russa no pensamento filosófico do século XX foi complexa e polifônica, e o exemplo de Dostoiévski, um pensador que, para Löwy, "se

\footnotetext{
4 Dentre suas obras, destacamos Redenção e utopia: messianismo judeu e utopia libertária na Europa Central; Romantismo e messianismo: ensaios sobre Lukács e Benjamin (São Paulo: Perspectiva, 2012); Para uma Sociologia dos intelectuais revolucionários (São Paulo: Editora Ciências Humanas, 1979); Revolta e melancolia: o romantismo na contramão da modernidade (Petrópolis: Vozes, 1995); A evolução política de Lukács: 1909-1929 (São Paulo: Cortez, 1998); Franz Kafka: sonhador insubmisso. (Azougue Editorial, 200); Walter Benjamín: aviso de incêndio. Uma leitura das teses "Sobre o conceito de História" (São Paulo: Boitempo, 2005).
} 
situa claramente no terreno da visão romântica de mundo", torna-se significativamente emblemático. Embora um romantismo contrarrevolucionário tenha encontrado no autor de Os irmãos Karamázov elementos que pudessem legitimar os anseios nacionalistas e de enraizamento que municiaram os teóricos de uma revolução conservadora (Moeller van den Bruck, Goebbels, Heidegger), a interpretação utópico-revolucionária do russo realizada por "judeus de cultura alemã" encontra-se entre as mais criativas páginas da filosofia moderna. A singularidade da análise oferecida por Michael Löwy sobre a tradição judaica e neorromântica representada por autores como Kafka, Lukács, Bloch e Benjamin é um material imprescindível para aqueles que buscam entender melhor a recepção e a influência da literatura russa, especialmente Dostoiévski e Tolstói, na constelação filosófica do judaísmo da primeira metade do século XX. A aproximação eletiva realizada pelo filósofo franco-brasileiro entre a "cultura espiritual" expressa nas obras de Dostoiévski e Tolstói e a condição histórica dos intelectuais judeus da Europa Central aparece aqui como um elemento sine qua non.

Uma anedota contada por Emmanuel Levinas, por ocasião de uma entrevista a François Poirié, revela que, ao receber em sua casa a visita de um israelense originário da Europa Oriental, o sujeito, após reconhecer nas estantes a obra completa de Púchkin, afirmou: "Dá pra ver imediatamente que estamos em uma casa judia". ${ }^{5} \mathrm{Na}$ entrevista que apresentamos - e, sobretudo, na grandeza da obra de Michael Löwy -, podemos encontrar pistas fundamentais para interpretar a proximidade espiritual entre uma tradição judaico-libertária da Europa Central e a grande literatura russa. Essa "Attractio Electiva", proveniente de uma intelligentsia judaica neorromântica em relação aos resíduos teológicos e utópicos que se encontram encarnados nas obras de Dostoiévski e Tolstói (resíduos que talvez sejam, eles mesmos, essencialmente judaicos), pode ser interpretada como o elemento mais explosivo do messianismo filosófico moderno.

5 POIRIÉ, François. Emmanuel Levinas: ensaio e entrevistas. São Paulo: Perspectiva, 2007. p. 53. 
Jimmy Sudário Cabral (RUS): Gostaria de começar com uma pergunta que o filósofo Ernst Bloch dirigiu ao senhor em 1974, durante uma entrevista que o senhor mesmo conduzia: ${ }^{6}$ por que Dostoiévski e Tolstói exerceram e ainda exercem uma influência tão forte na intelectualidade moderna e ocidental?

Michael Löwy (ML): É difícil - senão impossível - responder a essa pergunta... A influência é diferente em cada época e em cada país. Como se trata de grandes escritores, cuja obra toca questões essenciais da condição humana, não é surpreendente que tenham tanta influência. Sem dúvida, o fato de serem autores russos, inspirados por uma cultura espiritual muito diferente da civilização europeia ocidental, lhes permite tomar uma distância em relação a esta última, o que contribuiu para o interesse que despertaram.

RUS: Nas suas memórias sobre Max Weber, Paul Honigsheim ${ }^{7}$ mostrou como Tolstói e Dostoiévski estiveram presentes no imaginário e nas discussões sobre ética, filosofia e política no círculo Max Weber. Introduzindo os confrontos de Weber com a ética radical do último Tolstói, Honigsheim afirma que Weber, em seu artigo germinal, Duas éticas (Zwei Moralen), considerou que somente um homem que viveu como Tolstói o fez poderia invocar o Sermão da Montanha e proclamar os méritos do pacifismo e do desarmamento. Honigsheim ainda observa que, mesmo após a guerra, Weber sentia necessidade de se posicionar com mais clareza em relação à ética de Tolstói. O senhor poderia comentar esse fato?

ML: O círculo Max Weber de Heidelberg era, segundo o testemunho do próprio Honigsheim, um espaço no qual muitos dos participantes - escritores, filósofos, sociólogos - compartilharam a crítica romântica da civilização moderna. $O$ interes-

6 Disponível em: LÖWY, Michael. Pour une sociologie des intellectuels révolutionnaires. L'évolution politique de Lukacs, 1909-1929. pp. 318-330.

7 HONIGSHEIM, Paul. The Unknown Max Weber. New Brunswick, Nova Jérsei: Transaction Publishers, 2003. 
se pelos dois escritores russos certamente tem a ver com essa perspectiva dissidente. O próprio Max Weber partilhava, até certo ponto, essa crítica, como testemunham certos momentos de sua obra (p. ex., as páginas finais da Ética Protestante). Por outro lado, a discussão com as ideias de Tolstói corresponde à sua convicção de que inevitavelmente vivemos, na Modernidade, num universo de "guerra dos Deuses" (Kampf der Götter): o que para uns é um bem absoluto - p. ex., "a defesa da pátria" -, para outros é inaceitável, porque oposto ao imperativo cristão de paz e amor ao próximo (Tolstói). Weber não concorda com Tolstói, mas respeita seu compromisso intransigente com o Sermão da Montanha, de Cristo. Não sei se ele mudou de ideia depois da guerra, considerando o desastre que foi esse conflito e o imenso número de vítimas inúteis.

RUS: Em uma entrevista intitulada Imoralismo religioso e imoralismo político, Gershom Scholem afirmou que o movimento do Kibbutz foi atravessado por um forte élan religioso, e que poderia ser considerado uma versão judaica do ideal tolstoiano. ${ }^{8} \mathrm{O}$ senhor poderia comentar essa afirmação e falar um pouco sobre a recepção de Tolstói no horizonte da intelectualidade europeia no séc. XX?

ML: Tenho a impressão de que a dimensão religiosa do Kibbutz tem mais a ver com a tradição judaica veterotestamentária - a doutrina social dos profetas, o messianismo - do que com a religiosidade cristã de Tolstói. O que o Kibbutz tomou de Tolstói foi mais o culto à vida camponesa, à relação material e espiritual com a terra, à simplicidade austera do campesinato (em contraste com a corrupção da vida nas cidades). Não posso comentar sobre a recepção de Tolstói na Europa, tema demasiado amplo...

RUS: Em suas análises sobre o Romantismo, aprendemos como esse é um conceito complexo e, não raramente, está associado

8 SCHOLEM, Gershom. Les Cahiers de I'Herne. Éditions de l'Herne, 2009. p. 85-91. 
a uma tradição filosófica e política conservadora. A recepção de Dostoiévski pelo romantismo reacionário alemão é, nesse sentido, muito emblemática. Podemos citar aqui o romance de Joseph Goebbels, Michael - páginas de um destino alemão, no qual lemos: "Nós acreditamos em Dostoiévski como os nossos pais acreditavam em Cristo". ${ }^{9} \mathrm{O}$ senhor poderia comentar a recepção das obras de Dostoiévski no âmbito do conservadorismo romântico alemão?

ML: A obra de Dostoiévski se situa claramente no terreno da visão romântica do mundo, isto é, da crítica cultural da civilização (capitalista) ocidental moderna em nome de valores do passado. Trata-se de um pensamento profundamente ambivalente, permitindo leituras muito diferentes, e mesmo contraditórias. Na Alemanha, vários pensadores reacionários se referiam a Dostoiévski para desenvolver uma ideologia contrarrevolucionária. Foi o caso de Moeller van den Bruck, teórico da revolução conservadora, autor de um livro sobre Dostoiévski que teve muito impacto - assim como outros, de forma mais superficial, como o senhor Goebbels. Isso não impede que pensadores de esquerda, revolucionários, socialistas/comunistas tenham também se referido a Dostoiévski. É o caso do jovem Lukács, de Ernst Bloch, de Walter Benjamin. Não por acaso, todos eles intelectuais judeus...

RUS: No contexto das suas pesquisas em torno do pensamento de G. Lukács, observamos o desafio de explicar as divergentes interpretações da obra de Dostoiévski realizadas pelo autor de A teoria do romance ao longo dos anos de 30,40 e 50 do século XX. O senhor poderia comentar essas oscilações do pensamento de Lukács em relação à obra de Dostoiévski?

ML: No meu livro com Robert Sayre, Revolta e melancolia, existe um capítulo sobre Lukács que examina em detalhe essa estranha oscilação do filósofo húngaro em relação ao escri-

9 GOEBBELS, Joseph. Michael: Ein deutsches Schicksal in Tagebuchblättern. Munique: Zentralverlag der NSDAP, 1942. p. 34. 
tor russo. Enquanto o jovem Lukács propõe - em particular na Teoria do romance ${ }^{10}$ (1916) - uma leitura utópico/revolucionária de Dostoiévski, no final dos anos 20 ele publica um artigo que denuncia o escritor russo como expressão do caráter reacionário do romantismo anticapitalista. Essa orientação se mantém ao longo dos anos 30, mas, no início da Segunda Guerra Mundial, há uma nova virada, sendo mais uma vez Dostoiévski visto como figura utópica. E assim por diante... É difícil dar uma explicação clara dessas reviravoltas. Sem dúvida tem a ver com a atitude mais geral de Lukács em relação ao anticapitalismo romântico. Será que corresponde a mudanças na linha do movimento comunista? Francamente, não tenho resposta...

RUS: A formulação de E. Bloch de um "reino religioso coletivista de justiça no espírito de Dostoiévski" tem elementos que se aproximam do próprio conceito de "utopia" que encontramos no pensamento blochiano. No ensaio de Walter Benjamin sobre $O$ idiota, ${ }_{11}^{11}$ encontramos um horizonte um pouco diferente, possuidor de uma tonalidade mais pessimista e trágica e que talvez tenha discernido a existência de um "abismo insondável" no pensamento de Dostoiévski. O senhor poderia comentar as proximidades e diferenças na leitura de Benjamin e Bloch da obra de Dostoiévski?

ML: Desculpe, mas teria que fazer toda uma pesquisa para responder a essa pergunta. Mais uma vez nos confrontamos com a "polivalência" de Dostoiévski, cuja obra é ao mesmo tempo utópica e trágica. Talvez essa ambiguidade seja uma das razões do fascínio que ele exerce sobre o pensamento europeu. O utopista Bloch encontra em Dostoiévski elementos que legitimam $O$ princípio esperança:12 Aliócha Karamázov seria

10 LUKÁCS, Georg. A teoria do romance. Um ensaio histórico-filosófico sobre as formas da grande épica. São Paulo: Duas Cidades/Editora 34, 2000.

11 BENJAMIN, Walter. Escritos sobre mito e linguagem (1915-1921). São Paulo: Duas Cidades/Editora 34, 2013. pp. 75-80.

12 BLOCH, Ernst. O princípio esperança. Rio de Janeiro: Contraponto/Uerj, tomo 1, 2005; 
um precursor do "reino religioso da justiça". Walter Benjamin, partidário do "pessimismo em toda linha" (veja seu artigo de 1929 sobre o surrealismo ${ }^{13}$ ), interpreta o escritor russo como um autor trágico.

RUS: O entusiasmo de Heidegger pelas obras de Dostoiévski atravessou a trajetória desse filósofo e marcou suas reflexões sobre os conceitos de "niilismo" e "enraizamento". Podemos lembrar aqui o uso de Heidegger do Discurso sobre Púchkin, ${ }^{14}$ na conferência Nietzsche e o niilismo europeu, ${ }^{15}$ de 1949, e a citação de Os demônios: "Mas aquele que não tem povo também não tem Deus!”, nos Cadernos negros de 1939-1941.16 Numa carta de julho de 1920 à sua mulher, Elfride, Heidegger recomendou avidamente a leitura dos Politische Schriften, de Dostoiévski, e confessou que foi o autor de Os irmãos Karamázov quem lhe ensinou o significado de estar "enraizado em um solo". ${ }^{17}$ Sabe-se que os Escritos políticos de Dostoiévski povoaram o imaginário filosófico da revolução conservadora alemã e, por isso, não é sem surpresa que descobrimos, através de Gershom Scholem, que Walter Benjamin os considerava a obra política mais importante de que tinha conhecimento na época moderna. ${ }^{18}$ Tendo em vista as trincheiras opostas em que se encontravam Benjamin e Heidegger, como o senhor interpretaria a recepção da obra de Dostoiévski por esses dois pensadores?

tomo 2-3, 2006.

13 BENJAMIN, Walter. "O surrealismo". In: Obras Escolhidas I - Magia e técnica, arte e política. São Paulo: Ed. Brasiliense, 2012. p. 21-35.

14 DOSTOIÉVSKI, Fiódor. "Púchkin”. In: GOMIDE, Bruno (org.). Antologia do pensamento crítico russo (1802-1901). São Paulo: Editora 34, 2013. pp. 405-423.

15 HEIDEGGER, Martin. Nietzsche. v. II. Rio de Janeiro: Forense Universitária, 2007. p. 2122.

16 HEIDEGGER, Martin. Reflexiones XII-XV. Cuadernos Negros, 1939-1941. Editorial Trotta, 2019. p. 108.

17 HEIDEGGER, Martin. Alma mía! Cartas de Martin Heidegger a su mujer Elfide 1915-1970. Buenos Aires: Manantial, 2008. p. 120-121.

18 Politischen Schriften foi publicado em 1907 pela editora Piper. 
ML: Não me interesso por Heidegger, por isso não poderia responder a essa pergunta. Quando a Benjamin, respondi na questão anterior. Essas "trincheiras opostas" mais uma vez confirmam e ilustram o caráter maravilhosamente ambivalente da obra de Dostoiévski. Todas essas leituras se fundamentam em algum aspecto dessa obra, mas são inevitavelmente unilaterais. Obviamente considero a interpretação de Benjamin imensamente superior, do ponto de vista ético e humano, à de Heidegger.

RUS: Em sua obra sobre Franz Kafka, Max Brod nos informa que o autor de $O$ processo leu com entusiasmo Gógol, Tolstói e Dostoiévski, e que, deste último, apreciava especialmente $O$ adolescente. Brod nos conta que "uma vez" Kafka fez com exultação a leitura de um trecho da obra, "uma passagem sobre pedir esmola e enriquecer" ${ }^{19} \mathrm{~A}$ ideia de tornar-se um Rothschild, a absoluta contradição entre esmola e enriquecimento, a relação ilusória entre dinheiro e liberdade e o vínculo entre capitalismo, miséria e escravização são temas centrais em $O$ adolescente e aproximam-se da crítica de Kafka aos efeitos da civilização. Tendo em vista a "negatividade radical" que encontramos tanto na obra de Dostoiévski como na de Kafka, o senhor poderia nos dizer algo sobre uma possível "afinidade eletiva" entre os dois autores?

ML: Mais um exemplo de intelectual judeu que faz uma leitura libertária de Dostoiévski... Me parece que a afinidade eletiva entre os dois tem a ver com a visão de mundo romântica que ambos partilham. Ambos são críticos da civilização capitalista, baseada no dinheiro, na busca obsessiva pelo enriquecimento, na escravização dos seres humanos pelos aparelhos. Em Kafka, essa sensibilidade romântica toma uma coloração anarquista não sob forma de utopia, mas de "negatividade radical" diante do estado de coisas existente. Dostoiévski rompeu com os sonhos revolucionários de sua juventude, mas sua obra guarda essa dimensão da crítica radical que encantou Franz Kafka.

19 BROD, Max. Franz Kafka. Lisboa: Ed. Ulisseia, 1954. p. 38. 
RUS: Em sua obra Pour une sociologie des intellectuels révolutionnaires (1976), o senhor menciona a reinvindicação de Ernst Bloch, o qual considerou que na origem do messianismo romântico-revolucionário encontra-se uma tradição imemorial e subterrânea de misticismo e heresia. Nessa mesma direção, Theodor Adorno propôs uma relação entre o messianismo de Gershom Scholem e a tradição místico-subterrânea da apocatástase cristã. Para Adorno, ao tornar-se objeto de anátema no interior do cristianismo, tal mística influenciou profundamente a Igreja Oriental e, posteriormente, encarnou-se na grande literatura russa moderna ${ }^{20}$ Poderíamos falar, nesse sentido, de uma influência da literatura russa na reescritura do messianismo judaico moderno?

ML: Trata-se de uma bela hipótese, que mereceria uma pesquisa. Não estou seguro de que o messianismo de Scholem, ou de Benjamim, ou de Ernst Bloch, tenham a ver com a mística cristã ou com a literatura russa. Me parece que aqui as fontes judaicas, veterotestamentárias ou cabalísticas são mais relevantes. Quem mais se interessou pela religiosidade oriental e por Dostoiévski nesse contexto de espiritualidade mística foi Georg Lukács, em particular no seu manuscrito inacabado sobre Dostoiévski, redigido nos anos de 1915-18.

Vou propor agora uma pergunta que não foi feita: porque será que a maioria - senão a totalidade - dos autores que propõe uma leitura utópica, revolucionária e libertária de Dostoiévski são judeus de cultura alemã? Tem a ver, provavelmente, com a condição de semipária dos intelectuais judeus da Europa Central e com a adesão de muitos deles à visão romântica de mundo. Tentei abordar essas questões em meu livro Redenção e utopia: o judaísmo libertário na Europa Central.

20 ADORNO, Theodor. "Salut à Gershom Scholem Pour son 70e anniversaire". In: SCHOLEM, Gershom. Les Cahiers de l'Herne. Éditions de l'Herne, 2009. p. 171-175. 


\section{Referências bibliográficas}

BENJAMIN, W. Escritos sobre mito e linguagem (1915-1921). São Paulo: Duas Cidades/Ed. 34, 2013. p. 75-80.

BENJAMIN, W. O surrealismo. In: Obras Escolhidas I - Magia e técnica, arte e política. São Paulo: Ed. Brasiliense, 2012. p. 21-35.

BLOCH, E. O princípio esperança. Rio de Janeiro: Contraponto/ Uerj, tomo 1, 2005; tomo 2-3, 2006.

BOURETZ, P. Témoins du futur. Philosophie et messianisme. Paris: Éditions Gallimard, 2003. p. 18.

DOSTOIËVSKI, F. Púchkin. In: GOMIDE, B. Antologia do pensamento crítico russo (1802-1901). São Paulo: Ed. 34, 2013. p. 405-423.

GOEBBELS, J. Michael: Ein deutsches Schicksal in Tagebuchblättern. München: Zentralverlag der NSDAP, 1942. p. 34.

HEIDEGGER, M. Nietzsche. v. II. Rio de Janeiro: Forense Universitária, 2007. p. 21-22.

HEIDEGGER, M. Reflexiones XII-XV. Cuadernos Negros, 19391941. Editorial Trotta, 2019. p. 108.

HEIDEGGER, M. Alma mía! Cartas de Martin Heidegger a su mujer Elfide 1915-1970. Buenos Aires: Manantial, 2008. p. 120121.

HONINGSHEIM, P. The Unknown Max Weber. New Brunswick, New Jersey: Transaction Publishers, 2003.

LÖWY, M.; SAYRE, R. Revolta e melancolia: o romantismo na contracorrente da Modernidade. São Paulo: Boitempo, 2020.

LÖWY, M. Pour une sociologie des intellectuels révolutionnaires. L'évolution politique de Lukacs, 1909-1929. p. 318-330.

LÖWY, M. Redenção e utopia: o judaísmo libertário na Europa Central. São Paulo: Perspectiva, 2020.

LÖWY, M. Romantismo e messianismo: ensaios sobre Lukács e Benjamin (São Paulo: Perspectiva, 2012 
LÖWY, M. Franz Kafka: sonhador insubmisso. (Azougue Editorial, 2005)

LÖWY, M. Walter Benjamín: aviso de incêndio. Uma leitura das teses 'Sobre o conceito de História'(São Paulo: Boitempo, 2005). LÖWY, M. Revolta e melancolia: o romantismo na contramão da modernidade (Petrópolis: Vozes, 1995)

LÖWY, M. A evolução política de Lukács: 1909-1929 (São Paulo: Cortez, 1998)

LUKÁCS, G. A teoria do romance. Um ensaio histórico-filosófico sobre as formas da grande épica. São Paulo: Duas Cidades/ Ed. 34, 2000.

POIRIÉ, F. Emmanuel Levinas: ensaio e entrevistas. São Paulo: Perspectiva, 2007. p. SCHOLEM, G. Les Cahiers de l'Herne. Éditions de l'Herne, 2009. p. 85-91.

Tradução: Jimmy Sudário Cabral

Revisão textual por Eliana Moura Carvalho Mattos.

Recebido em: 25/02/2021 Aceito em: 11/03/2021 Publicado em abril de 2021 